\title{
A Fast Hough Transform Based on a Sine-Three-Term-Recurrence
}

\author{
Munetoshi Numada Non-member (Lossev Technology, m-numada@lossev.co.jp) \\ Hiroyasu Koshimizu Senior Member (Chukyo university, hiroyasu@sist.chukyo-u.ac.jp)
}

Keywords : line detection, Hough transform, three-term-recurrence, shift operation

The Hough transform (Eq. (1)) is an important method for pattern recognition that allows a line to be detected from the edge points of an image ${ }^{(1)}$. In the attempt to achieve a faster Hough transform, it is found most practical to increase the efficiency of both the trigonometric function that forms the basic computational unit, and multiplication. For this reason, Koshimizu et al. proposed a method "Fast Incremental Hough Transform 2 (FIHT2)" that enables one point to be generated on the curve by a single operation of multiplication ${ }^{(2)}$. To be more specific, this is actually a method for determining a Hough curve approximatively and incrementally using a simultaneous recurrence formula. However, it has a problem that a significant approximation error occurs. Therefore, a method for making this recurrence formula more accurate was then proposed, which resulted in more or less doubling the computation cost in software processing. With this shortcoming taken into consideration, this paper proposes a method "FIHT3" (Eq.(2)) that generates an accurate Hough curve using an STTR (Sine-Three-Term-Recurrence).

$$
\left.\begin{array}{l}
\rho_{n}=x \cdot \cos \theta_{n}+y \cdot \sin \theta_{n} \\
\rho_{n}^{\prime}=-x \cdot \sin \theta_{n}+y \cdot \cos \theta_{n}
\end{array}\right\}
$$

As with the FIHT2, the FIHT3 method is based on a single operation of multiplication for determination of one point. Moreover, high-speed algorithm which uses shift operation instead of multiplication was also shown in this paper. The computation time of the original Hough transform is $5.23 \times 10^{-1} \mathrm{sec}$, and the

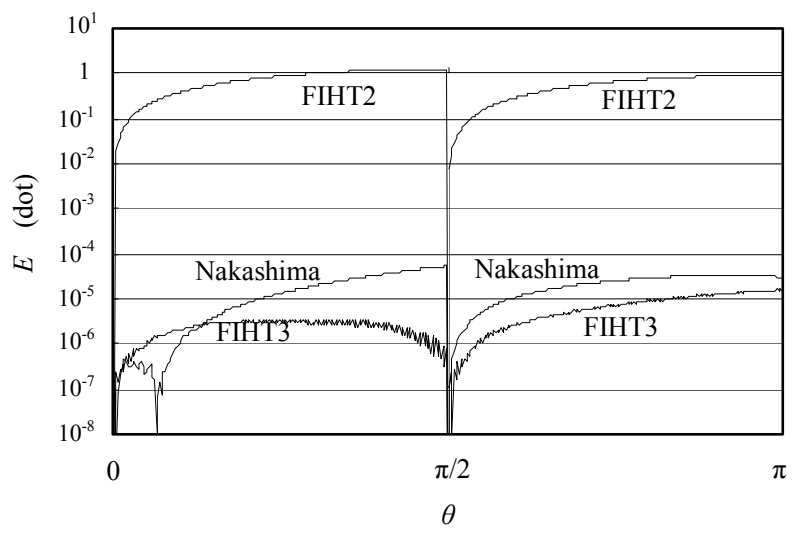

Fig. 1. Deviation $E$ to Hough curve.

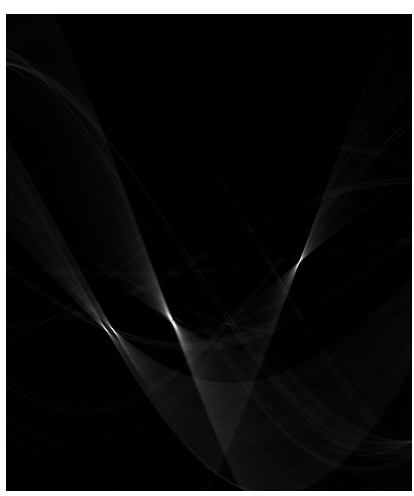

(a) Processed by Hough transform

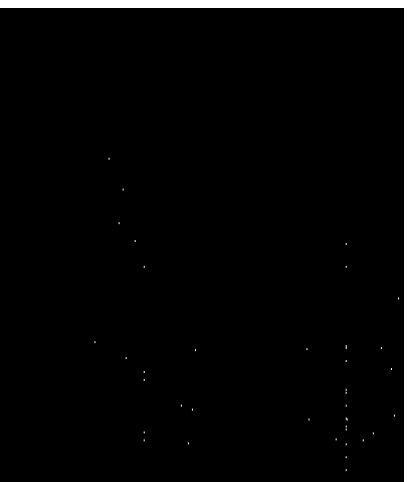

(c) Deviation (Nakashima's method)

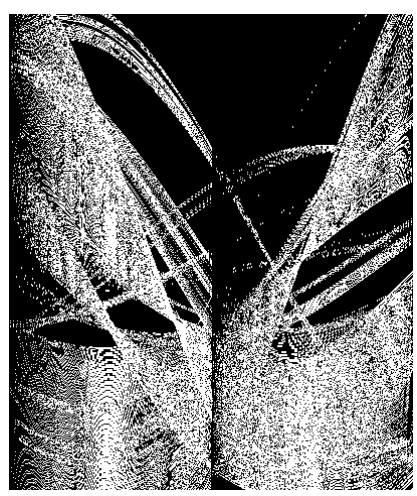

(b) Deviation (FIHT2)

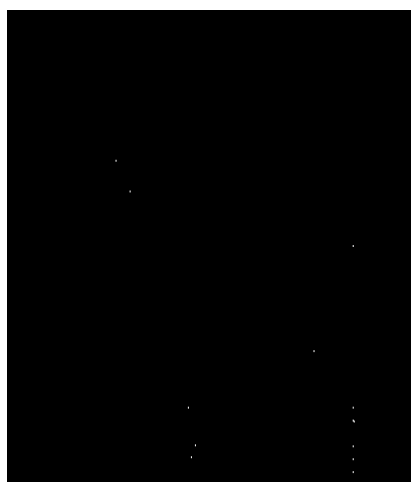

(d) Deviation (FIHT3)
Fig. 2. Deviation between Hough transform and other methods.

processing time ratio to the FIHT3 was 20.2. as follows:

Computational time (sec)

$\begin{array}{llll} & \text { FIHT2 } & \text { Nakashima }^{(3)} & \text { FIHT3 } \\ \text { Time } & 3.03 \times 10^{-2} & 2.84 \times 10^{-2} & 2.59 \times 10^{-2} \\ \text { Ratio } & 1.17 & 1.10 & 1.00\end{array}$

Furthermore, doing experiments has confirmed that the FIHT3 method provides the best accuracy and the fastest computation among any other methods that employ the conventional simultaneous recurrence formula (Fig. 1, Fig.2).

\section{References}

(1) R. O. Duda and P. E. Hart : Use of the Hough transform to detect lines and curves in pictures, Comm. ACM, Vol.15, No.1, pp.11-15 (1972)

(2) H. Koshimizu and M. Numada : FIHT2 algorithm, a fast incremental Hough transform, IEICE Trans., Vol.E 74, No.10, pp.3389-3393 (1991)

(3) K. Nakashima, H. Yakabe, Y. Obuchi, and K. Inoue : High-speed, high-accuracy Hough transform using simultaneous recurrence formula, Systems and Computers in Japan, Vol.28, No.3, pp.24-33 (1997) 


\title{
正弦三項漸化式に基づく高速 Hough 変換
}

\author{
非会員 沼田＼cjkstart宗敏 $* * *$ 上級会員 輿水 大和**
}

\author{
A Fast Hough Transform Based on a Sine-Three-Term-Recurrence \\ Munetoshi Numada*, Non-member, Hiroyasu Koshimizu**, Senior Member
}

\begin{abstract}
Hough transform (HT) is one of the important methods for detecting or recognizing lines from the edge points in the image. In order to put HT faster, it is promising to decrease the computation costs both in the trigonometric function that forms the basic computational unit and in multiplication. From this view point, Koshimizu et al. proposed a method "Fast Incremental Hough Transform 2 (FIHT2)" that enables one point to be generated on the curve by a single operation of multiplication. However, it has a problem that a significant approximation error occurs. With this shortcoming taken into consideration, this paper proposes a new method "FIHT3" that generates an exact Hough curve using a STTR (Sine-Three-Term-Recurrence). As with FIHT2, FIHT3 method is implemented by a single operation of multiplication for generating one point of Hough curve. Furthermore, it was known experimentally that the FIHT3 method provides the complete accuracy and the fastest computation among any other methods that employ the conventional simultaneous recurrence formula. Moreover, the high-speed algorithm which uses shift operation instead of multiplication was also shown in this paper.
\end{abstract}

キーワード : 直線検出, Hough 変換, 三項漸化式, シフト演算

Keywords : line detection, Hough transform, three-term-recurrence, shift operation

\section{1. はじめに}

Hough 変換 ${ }^{(1)}$ は, クラスタリングされていないエッジ点群 から直線を検出できる，パターン認識の有力な手法である。 この手法は，パターン平面上のエッジ点をパラメータ平面 上の曲線へと変換し, 同一直線上にある点群の変換曲線が パラメータ平面上で交差する性質を利用する。しかし，処 理時間の大きさが障害となっている。これは, 次式に示す Hough 変換の基本式に含まれる, 三角関数演算と乗算の計 算コストが大きいためである。

$$
\rho_{n}=x \cdot \cos \theta_{n}+y \cdot \sin \theta_{n}
$$

ここに, パラメータ $\rho$ はパターン平面である $x-y$ 座標系の エッジ点の画像の原点から直線までの距離, パラメータ $\theta$ は原点から直線に下ろした垂線と $x$ 軸とのなす角度である。

これまで Hough 変換を高速化するため多くの研究が行わ れているが，大別するとハードウェアを用いる手法，演算 回数の低減を図る手法，基本演算部を効率化する手法の 3

\footnotetext{
* (株) ロゼフテクノロジー

干939-1502 富山県南砺市野尻 662-1

Lossev Technology Corp.

662-1 Nojiri, Nanto-shi 939-1502

** 中京大学情報理工学部

T470-0393 愛知県豊田市貝津町床立 101

School of Information Science and Technology, Chukyo University 101 Tokodachi, Kaizu-cho, Toyota-shi 470-0393
}

種類に分けることができる。 まず，ハードウェアを用いる手法であるが，これは専用 ハードウェアを用いて高速に Hough 変換を実行する手法で ある。これには, CORDICによる反復演算を用いる $\mathrm{FPGA}^{(2)}$, マルチプロセッサ構成や(3), 角度分割数を 2 のべき乗とし FFT のようなバタフライ演算を多段パイプラインで実現す る並列回路(4)などがある。しかし，これらはいずれも初期投 資が大掛かりであり，ソフトウェア処理で置き換えた場合 には効率化がほとんど見込めないハードウェアのみに特化 した手法である。

第 2 の演算回数の低減を図る手法には，まず，ピラミッ ド構造を用いた手法がある(5)。これは, 高解像度の画像から 低解像度の画像までピラミッドのように階層化を行い, エ ッジ点数を減らすことによって, 演算回数を低減する手法 である。しかし, 階層化の次数が大きくなるにつれ, 線分 の特徵である長さが指数関数的に小さくなるため, 短い線 分の抽出には適さない。一方, エッジ成分の勾配を用いる 手法は ${ }^{(6)(7)}$ ，投票する角度パラメータ $\theta$ の範囲を制限し，演 算回数を低減する手法である。しかし, エッジ成分の勾配 はノイズの影響を受けると大きく変化する。このため，， イズが含まれるエッジ画像にこの手法を適用すると正しく 直線を検出できない。したがって, Hough 変換の特長の一 つである，ノイズに対するロバスト性が失われてしまって いる。 
第 3 の基本演算部の計算コストを効率化する手法は，計 算コストの大きな三角関数演算と乗算の計算回数とを削減 する。実際には，三角関数は予め計算しテーブル化してお くことにより省くことができるので，乗算回数の低減が鍵 となる。この手法による最初の試みはOndaらによるもので, 三角関数の周期性を利用した効率的な計算手法を提案し た ${ }^{(8)}$ 。これは, 角度パラメータ $\theta$ を $M$ 個のブロックに分け る手法で, Hough 曲線上の 1 点あたりの乗算回数を 2 回か ら 3/2+1/M 回にまで低減させた。しかし, この手法で効率を 上げるには分割数 $M$ を十分に大きくする必要があり, こう すると逆にステップ数が $M$ 倍に大きくなってしまうという 問題があった。

これに対し，漸化式を用いてインクリメンタルに近似 Hough 曲線を発生させることのできる, 著者らによる PLHT 法およびFIHT2, Tagzout らによる改良 FIHT2 などが提案さ れている(9)〜(11)。これらは(1)式の Hough 変換とは異なる変 換関数系を用いる広義の Hough 変換で, 同一関数による逆 変換で直線を検出するので, 検出される直線には近似誤差 が伴わない。また，これらの曲線はインクリメンタルに計 算できるので, 1 点を生成するのに必要な乗算回数がほぼ 1 回ですむ。第 1 の PLHT 法では Hough 曲線を区分的直線で 近似した Hough 曲線を用い, 第 2 の FIHT2 では Hough 曲線 に対して数 dot 程度の偏差をもつ近似 Hough 曲線を用いる。 ここに, 単位 [dot] はパラメータ平面の分割の最小単位であ る。第 3 の改良 FIHT2 では, 直列演算方式の FIHT2 よりも ハードウェア化に適した並列演算方式の漸化式を用いる が, Hough 曲線との近似誤差は FIHT2 を用いた場合に比べ て 2 倍ほど大きくなる。これに対し, Nakashima らは近似 Hough 曲線計算の漸化式を改良し, Hough 曲線との近似誤差 を $10^{-4} \mathrm{dot}$ 以下に抑えた ${ }^{(12)}$ 。この手法はハードウェア化に適 した並列演算方式の漸化式を用いる。しかしながら，1点あ たりの乗算回数は 2 回と多く, ソフトウェアで実行すると FIHT2 などに比べ 2 倍の処理時間を要する。

このような漸化式を用いた基本演算部の効率化の背景か ら, 1 点あたりの乗算回数が 1 回以下, Hough 曲線との近似 誤差が $10^{-4} \mathrm{dot}$ 以下, 並列演算方式, ステップ数が小さい, という 4 つの条件を同時に成立させることのできる Hough 変換法が求められている。このような手法は, ソフトウェ ア, ハードウェアのいずれで実行しても従来法よりも高速 高精度となることが期待される。そこで本論文では, 正弦 三項漸化式を用いてこのような Hough 変換法を提案する。

以下，2 章では漸化式を用いた従来の Hough 変換法につ いて概説する。続く 3 章では正弦三項漸化式を用いて, 㛜 密な Hough 曲線を効率よく発生させる手法を提案する。 4 章の実験では計算コストと近似誤差の分析を行い，5章で全 体をまとめる。

\section{2. 漸化式を用いた従来の Hough 変換法}

〈2·1〉 FIHT2 FIHT2 では次の漸化式を用いて, $\rho_{n}$ とこれのペアである $\rho_{n}^{\prime} \cong \rho_{n+K / 2}$ を計算する ${ }^{(10)}$ 。ここで, $K を$ $\theta$ 方向分割数とし, $n=0,1, \ldots, K / 2-2$ とする。また, $\varepsilon$ を十分 に小さな定数とする。

$$
\left.\begin{array}{l}
\rho_{n+1}=\rho_{n}+\varepsilon \cdot \rho_{n}^{\prime} \\
\rho_{n+1}^{\prime}=\rho_{n}^{\prime}-\varepsilon \cdot \rho_{n+1}
\end{array}\right\}
$$

(2)式を解いて次式を得る。

$$
\left.\begin{array}{c}
\rho_{n}=\frac{\rho_{0} \cos \left(\theta_{n}-\Delta \theta / 2\right)+\rho_{0}^{\prime} \sin \theta_{n}}{\cos (\Delta \theta / 2)} \\
\rho_{n}^{\prime}=\frac{-\rho_{0} \sin \theta_{n}+\rho_{0}^{\prime} \cos \left(\theta_{n}+\Delta \theta / 2\right)}{\cos (\Delta \theta / 2)}
\end{array}\right\}
$$

ただし $, \Delta \theta=\pi / K, \varepsilon=2 \sin (\Delta \theta / 2), n \Delta \theta=\theta_{n}$ とする。 $\varepsilon$ が十分に小 さいとき, $\Delta \theta=2 \sin ^{-1}(\varepsilon / 2) \cong 0, \cos (\Delta \theta / 2) \cong 1$ が成立する。こ のため, 初期值 $\rho_{0}=x, \rho_{0}^{\prime}=y$ とおくことにより,

$$
\left.\begin{array}{rl}
\rho_{n} & \cong x \cos \theta_{n}+y \cdot \sin \theta_{n} \\
\rho_{n}^{\prime} & \cong-x \sin \theta_{n}+y \cdot \cos \theta_{n} \\
& =x \cdot \cos \left(\theta_{n}+\pi / 2\right)+y \cdot \sin \left(\theta_{n}+\pi / 2\right)
\end{array}\right\}
$$

となり，(1)式の近似式が得られる。すなわち，(2)式の漸 化式をインクリメンタルに計算することにより, (1)式の近 似 Hough 曲線である(4)式を得ることができる。ここで, 図 1 に FIHT2 による近似 Hough 曲線発生の手順を示す。まず, $\theta$ 方向分割数 $K$ を 2 の倍数とおく。次に初期值を $\rho_{0}=x, \rho_{0}^{\prime}=y$ とおく。そして, (2)式の漸化式を $K / 2-1$ 回繰り返して計算 すると, 近似 Hough 曲線を発生できる。 $\rho_{n}$ または $\rho_{n}^{\prime}$ を 1 点 計算するための乗算回数は 1 回である。また, Hough 曲線 との近似誤差 $E$ は $\rho_{n}$ の近似誤差を $E_{n}$ として,

$$
\left.\begin{array}{ll}
E_{n} \cong \frac{\pi}{2 K}\left|x \cdot \sin \theta_{n}\right| \leq \frac{\pi}{2 K}|x| & \left(0 \leq \theta_{n}<\frac{\pi}{2}\right) \\
E_{n} \cong \frac{\pi}{2 K}\left|y \cdot \cos \theta_{n}\right|<\frac{\pi}{2 K}|y| & \left(\frac{\pi}{2} \leq \theta_{n}<\pi\right)
\end{array}\right\}
$$

であるから ${ }^{(10)}$,

$$
E \leq \frac{\pi}{2 K} \max (|x|,|y|)
$$

となる。

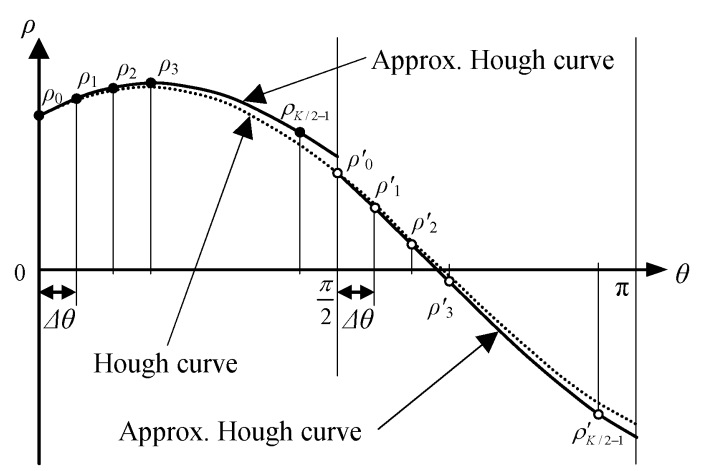

Fig. 1. Generating the approximated Hough curve by using FIHT2, 
〈2·2〉 改良 FIHT2 Tagzout らの改良 FIHT2 は ${ }^{(9)},(2)$ 式の 2 行目右辺第 2 項の $\rho_{n+1}$ を $\rho_{n}$ に置き換えた手法である。

$$
\left.\begin{array}{l}
\rho_{n+1}=\rho_{n}+\varepsilon \cdot \rho_{n}^{\prime} \\
\rho_{n+1}^{\prime}=\rho_{n}^{\prime}-\varepsilon \cdot \rho_{n}
\end{array}\right\}
$$

(2)式をハードウェアで実行する場合， 2 行目の $\rho_{n+1}^{\prime}$ は 1 行目の $\rho_{n+1}$ の計算が終わってからでないと計算できない。よ ってこの式は直列演算方式である。これに対し，(7)式は 1 行目と 2 行目を同時に計算できる並列演算方式である。こ のため, 並列処理可能なハードウェアで実行するとより高 速化できる。しかし，この式で計算した Hough 曲線との近 似誤差は, FIHT2 で計算した場合に比べて約 2 倍と大きく, 実用向きではない。

〈2·3〉 Nakashima らの手法 Nakashima らは(2)式 を改良し, (1)式の Hough 曲線との近似誤差がより小さくな る連立漸化式を提示した。これを下に示す。

$$
\left.\begin{array}{l}
\rho_{n+1}=\rho_{n}-\frac{\delta^{2}}{2} \cdot \rho_{n}+\delta \cdot \rho_{n}^{\prime} \\
\rho_{n+1}^{\prime}=\rho_{n}^{\prime}-\frac{\delta^{2}}{2} \cdot \rho_{n}^{\prime}-\delta \cdot \rho_{n}
\end{array}\right\}
$$

ここに変数 $\delta$ と刻み角 $\Delta \theta=\pi / K$ との間には,

$$
\sin \Delta \theta=\delta / \sqrt{1+\delta^{4} / 4}
$$

の関係が成り立つ。ここで， $\delta$ を $2^{-m}$ の形にすると $\delta^{2} / 2$ は $2^{-(2 m+1)}$ の形になる。このため, $(8)$ 式は乗算の代わりに, よ り高速なシフト演算を用いて計算できる。これをハードウ エ化した場合, 2 回のシフト演算を同時に処理することがで きるので, 1 回のシフト演算を用いる場合と処理時間は変わ らない。さらに，(8)式は改良 FIHT2 と同様並列演算方式で あるので，ハードウェア化の実験例では，直列演算方式の FIHT2 に比べて約 1.5 倍高速であるという報告がある(12)。

また, Hough 曲線(1)式との近似誤差 $E$ は次式で計算でき る。すなわち, $\delta \cong \Delta \theta=\pi / K$ であるので,

$$
\begin{aligned}
E & \leq\left\{\left(\sqrt{1+\frac{\delta^{4}}{4}}\right)^{\frac{K}{2}}-1\right\} \max (|x|,|y|) \quad \ldots \ldots \ldots . . . \\
& \cong \frac{K \delta^{4}}{16} \max (|x|,|y|) \cong \frac{\pi^{4}}{16 K^{3}} \max (|x|,|y|)
\end{aligned}
$$

となる ${ }^{(12)}$ 。これは, FIHT2 と比べて十分に小さい。

しかし，(8)式をソフトウェアで実行すると， $\delta^{2} / 2$ を予め 計算しておいたとしても, 乗算回数は 1 点あたり 2 回であ り FIHT2 の 2 倍になる。このため, ソフトウェアで実行す ると約 2 倍の処理時間を要する。

\section{3. 正弦三項漸化式を用いた Hough 变換}

〈3·1〉 三項漸化式を用いた計算手法 ここでは正弦 関数の定義式から導かれる正弦三項漸化式を用いて, 近似 誤差のない Hough 曲線を 1 点あたり 1 回の乗算で計算する 手法を提示する。まず次の正弦関数の定義式を考える。

$$
e^{i \Delta \theta}-e^{-i \Delta \theta}=2 i \sin \Delta \theta
$$

ここで，両辺に $e^{i \theta_{n}}$ を乗じれば次式を得る。

$$
e^{i \theta_{n+1}}-e^{i \theta_{n-1}}=2 i \sin \Delta \theta \cdot e^{i \theta_{n}}
$$

上式の実数部と虚数部から，以下の一対の漸化式を得る。

$$
\left.\begin{array}{l}
\cos \theta_{n+1}-\cos \theta_{n-1}=-2 \sin \Delta \theta \cdot \sin \theta_{n} \\
\sin \theta_{n+1}-\sin \theta_{n-1}=2 \sin \Delta \theta \cdot \cos \theta_{n}
\end{array}\right\}
$$

式の 2 つの成分は互いに絡み合って分離できない連立形で, 乗数係数に正弦関数を含む。これを正弦三項漸化式 STTR (Sine-Three-Term-Recurrence)という。上式の 1 行目に $x, 2$ 行目に $y$ を乗じた後に 2 つ式を加え, これに(1)式を代入 すると次式が得られる。

$$
\rho_{n+1}-\rho_{n-1}=2 \sin \Delta \theta \cdot \rho_{n}^{\prime}
$$

ここに, $\rho_{n}^{\prime}$ は $\rho_{K / 2+n}$ に等しく,

$$
\rho_{n}^{\prime}=-x \cdot \sin \theta_{n}+y \cdot \cos \theta_{n} \ldots
$$

である。 $K$ は $\theta$ 方向分割数で 2 の倍数である。同様に, (13) 式の 1 行目に $y, 2$ 行目に $x$ を乗じ， 2 つの式を減算すると 次式が得られる。

$$
\rho_{n+1}^{\prime}-\rho_{n-1}^{\prime}=-2 \sin \Delta \theta \cdot \rho_{n}
$$

$c=2 \sin \Delta \theta$ と置き換え, (14)と(16)式を連立させると, 次式の 連立漸化式を得る。

$$
\left.\begin{array}{l}
\rho_{n+2}=\rho_{n}+c \cdot \rho_{n+1}^{\prime} \\
\rho_{n+2}^{\prime}=\rho_{n}^{\prime}-c \cdot \rho_{n+1}
\end{array}\right\}
$$

$\rho_{0}$ と $\rho_{1}, \rho_{0}^{\prime}$ と $\rho_{1}^{\prime}$ を初期值として与え, $n=0$ から $K / 2-3$ まで 上式を計算すると順次 Hough 曲線が得られる。発生する Hough 曲線には近似誤差が伴わない。初期值は(1)式と(15) 式とから計算できる。このため, $\sin \Delta \theta, \cos \Delta \theta$ を定数化し ておけば, 初期值の計算も含めて三角関数の計算は一切不 要となる。また, Hough 曲線 1 点を生成するための乗算回 数も FIHT2 と同じ 1 回である。以下に, 提案手法のアルゴ リズムを示す。

[Initialize]

$$
\begin{aligned}
& \Delta \theta=\pi / K ; \alpha=\cos \Delta \theta ; \beta=\sin \Delta \theta ; c=2 \beta \\
& \rho_{0}=x ; \rho_{0}^{\prime}=y ; \rho_{1}=\alpha x+\beta y ; \rho_{1}^{\prime}=-\beta x+\alpha y
\end{aligned}
$$

[loop] $n=0,1,2, \cdots, K / 2-3$

$$
\begin{aligned}
& \rho_{n+2}=\rho_{n}+c \cdot \rho_{n+1}^{\prime} \\
& \rho_{n+2}^{\prime}=\rho_{n}^{\prime}-c \cdot \rho_{n+1}
\end{aligned}
$$

メインループのステップ数は FIHT2 と同様わずか 2 行と 少ない。しかも， $\rho^{\prime}{ }_{n+2}$ の計算に $\rho_{n+2}$ の計算結果を用いない並 列演算形式である。ここで, 本手法で発生した点列を図 2 に示す。これらの点列は, FIHT2, Nakashima らの手法とは 


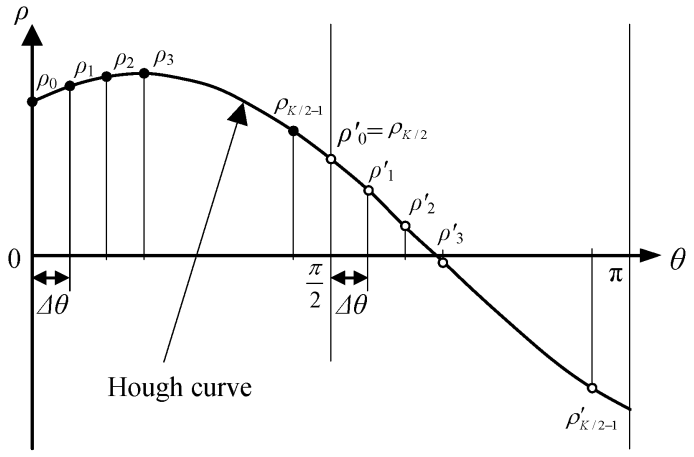

Fig. 2. Generating the Hough curve by using FIHT3.

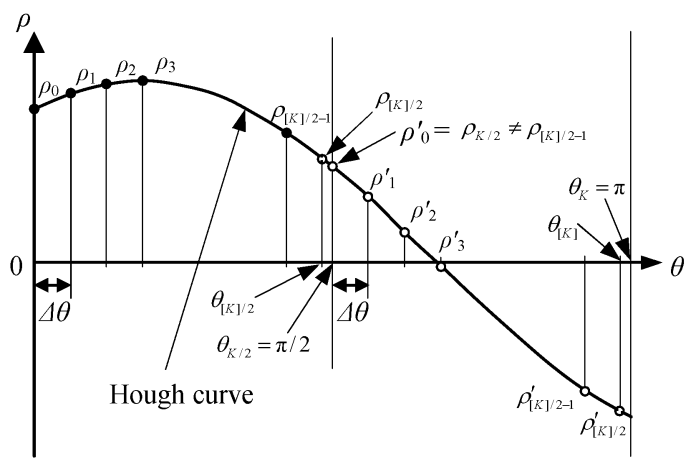

Fig. 3. Generating the Hough curve based on FIHT3 by using shift-operator.

異なり，㛜密な Hough 曲線である。この手法を Fast Incremental Hough Transform 3 (FIHT3) と呼ぶことにする。

〈3·2〉シフト演算による高速化 FIHT2 や Nakashima らの手法と同様, 乗数係数を 2 のべき乗に設定することに より，乗算をシフト演算に置き換えることができる。この ためより高速化が可能である。 $m$ を正の整数として, $c=$ $2 \sin \Delta \theta=2^{-m}$ とおくと, (17)式より次式が成立する。

$$
\left.\begin{array}{l}
\rho_{n+2}=\rho_{n}+\frac{\rho_{n+1}^{\prime}}{2^{m}} \\
\rho_{n+2}^{\prime}=\rho_{n}^{\prime}-\frac{\rho_{n+1}}{2^{m}}
\end{array}\right\}
$$

ただし, $\Delta \theta=\sin ^{-1}\left(2^{-m-1}\right), K=\pi / \Delta \theta$ である。(18)式と等価な Hough 変換の式は，(1)と(15)式である。これより， $\rho_{n}, \rho_{n}^{\prime}$ の初期 值は $\rho_{0}=x, \rho_{1}=x \cdot \cos \Delta \theta+y \cdot \sin \Delta \theta, \rho_{0}^{\prime}=y, \rho^{\prime}{ }_{1}=-x \cdot \sin \Delta \theta+y \cdot \cos \Delta \theta$ で与えられる。

ここで注意しなければならないのは， $\theta$ 方向分割数が $K=\pi / \sin ^{-1}\left(2^{-m-1}\right)$ という無理数となるため, 2 の倍数にならな い点である。このため，Kの代わりに整数である $[K] を$ 用い て漸化式を計算することにする。ここに，[] である。 $[K]$ が 2 の倍数であれば，(18)式の $n$ の範囲を $n=0,1,2, \cdots,[K] / 2-3$ とすればよい。

図 3 に示すように，(18)式で計算される点 $\left(\theta_{n}, \rho_{n}\right)$ は Hough 曲線上の点であり， $\theta$ 方向の間隔は $\Delta \theta$ で一定である。ただ し, $\theta_{[K] / 2-1}$ と $\theta_{K / 2}=\pi / 2, \theta_{[K]-1}$ と $\theta_{K}=\pi$ の間だけは, $\Delta \theta よ り$ も間隔が大きくなる。これは， $\theta_{[K] / 2} \neq \pi / 2, \theta_{[K]} \neq \pi$ とはなら
Table 1. Ratio of angle error $\gamma$.

\begin{tabular}{|c|l|l|l|l|l|}
\hline$m$ & 1 & 3 & 4 & 6 & 7 \\
\hline$c$ & 1 & $2^{-3}$ & $2^{-4}$ & $2^{-6}$ & $2^{-7}$ \\
\hline$K$ & 12.43 & 50.23 & 100.5 & 402.1 & 804.2 \\
\hline$[K]$ & 12 & 50 & 100 & 402 & 804 \\
\hline$\gamma$ & 0.22 & 0.12 & 0.26 & 0.06 & 0.12 \\
\hline
\end{tabular}

ないためである。この誤差の $\Delta \theta$ に対する比率を $\gamma$ とおくと,

$$
\gamma=\frac{\left(\theta_{K / 2}-\theta_{[K] / 2-1}\right)-\Delta \theta}{\Delta \theta}=\frac{K-[K]}{2}
$$

となる。この比率が大きいと, $\theta=\pi / 2$ 近辺と $\theta=\pi$ 近辺の直線 検出感度が低下寸る。 $m=1,3,4,6,7$ の場合の乗数係数 $c, \theta$ 方 向分割数 $K$ および $[K]$, 誤差の比率 $\gamma$ を表 1 に示した。 $m=2,5$ の場合は $[K]$ が 2 の倍数にならないので除いてある。これよ り, $m=6, c=2^{-6},[K]=402$ のとき最も $\gamma$ が小さくなることが わかった。

ここで, $m$ ビットのシフト演算を用いた Hough 曲線の計 算手順を示す。まず，画像中心を原点とする $H \times V$ pixel サ イズのエッジ画像を用いる。 $\rho$ 方向の 1 dot $x-y$ 座標系の 画像の 1 pixel と等しくすると, $|\rho|$ の最大值は $\max |\rho|=$ $\sqrt{(H / 2)^{2}+(V / 2)^{2}}$ となるため, $\rho$ 方向の分割数は $L=2 \max |\rho|=$ $\sqrt{H^{2}+V^{2}}$ とすればよい。シフト演算で用いる変数は整数で あるから，予め $\rho_{n}, \rho_{n}^{\prime}$ を $M$ 倍した $R_{n}, R_{n}^{\prime}$ を用いて計算を行 う。そして, 投票値の更新を行う直前に, $R_{n}, R_{n}^{\prime}$ を $M$ で割 って $\rho_{n}, \rho_{n}^{\prime}$ を求めるのがよい。 $M$ も高速化のために 2 のべ き乗, すなわち $p$ を正の整数として $M=2^{p}$ という形にしてお く。整数を 32 ビットで表現すると,

$$
\max |M \rho| \leq 2^{31}
$$

が成立するので, $L=2 \max |\rho|$ を代入して,

$$
L \leq 2^{32-p}
$$

が成立するような最大の $p$ を決定すればよい。たとえば, エッジ画像が $H=640, V=480$ の VGA 画像であれば $L=800$ と なるので, $p$ の取り得る最大值は 22 となる。

[Initialize]

$$
\begin{aligned}
& c=2^{-m} ; \Delta \theta=\sin ^{-1}(c / 2) ; K=\pi / \Delta \theta ; \\
& \alpha=\cos \Delta \theta ; \beta=c / 2 ; \\
& R_{0}=[x M] ; R_{0}^{\prime}=[y M] ; \\
& R_{1}=[(\alpha x+\beta y) M] ; R_{1}^{\prime}=[(-\beta x+\alpha y) M]
\end{aligned}
$$

[loop] $n=0,1,2, \cdots,[K] / 2-3$

$$
\begin{aligned}
& R_{n+2}=R_{n}+\left[R_{n+1}^{\prime} / 2^{m}\right] \\
& R_{n+2}^{\prime}=R_{n}^{\prime}-\left[R_{n+1} / 2^{m}\right]
\end{aligned}
$$

上式の[loop]の $R_{n+2}, R_{n+2}^{\prime}$ における計算の平均誤差は, 整数 演算であるから 0.5 である。これが $[K] / 2-2$ 回繰り返される ので, 累積誤差は $e \fallingdotseq[K] / 4-1$ となる。 $\rho_{n+2}, \rho_{n+2}^{\prime}$ は $R_{n+2}, R_{n+2}^{\prime}$ を $M=2^{p}$ で割って得られるので,

$$
E \approx 2^{-p-2}([K]-1) \approx 2^{-(p+2)} K
$$


Table 2. Number of multiplications and shift operations.

\begin{tabular}{|l|c|c|c|}
\hline & FIHT2 & Nakashima & FIHT3 \\
\hline Multiplications & 1 & 2 & 1 \\
\hline Shift operations & 1 & 2 & 1 \\
\hline
\end{tabular}

Table 3. The theoretical deviations (dot).

\begin{tabular}{|l|c|c|c|}
\hline & FIHT2 & Nakashima & FIHT3 \\
\hline Multiplications & $\pi L / 5 K$ & $E_{1}: \pi^{4} L /\left(40 K^{3}\right)$ & 0 \\
\hline Shift operations & $\pi L / 5 K$ & $\sqrt{E_{1}^{2}+E_{2}^{2}}$ & $E_{2}: 2^{-(p+2)} K$ \\
\hline
\end{tabular}

となる。なお，付録 A. 1 に上記アルゴリズムの C 言語によ るプログラムを添付した。

〈3.3〉 計算コストと誤差の評価ＦIHT2, Nakashima らの手法及び提案手法の FIHT3 とで, $\rho-\theta$ パラメータ平面上 に描く軌跡の 1 点を出力するための乗算回数について調べ, 表 2 に示した。FIHT2 及び FIHT3 では, 1 回の乗算で近似 Hough 曲線または Hough 曲線の 1 点を計算できる。これに 対し, Nakashima らの手法では 2 回の計算が必要である。乗 算をシフト演算に置き換えた場合の計算回数も同様である。

また, Hough 曲線と各手法の生成曲線との近似誤差を調 べるため, 便宜上エッジ画像（ $H \times V$ pixel） の縦横比を 4:3 とした。これより, $\rho$ 方向の分割数は, $L=(5 / 2) \max (|x|,|y|)=$ (5/4)H となる。この近似誤差を表 3 に示寸。FIHT2 の近似誤 差は(6)式に, $\max (|x|,|y|)=(2 / 5) L$ を代入して $\pi L / 5 K$ となる。 $L=800, K=402$ なら $1.25 \mathrm{dot}$ と無視できないほど大きい。これ に対し, Nakashima らの手法の近似誤差は, (10)式より $E=\pi^{4} L /\left(40 K^{3}\right)$ となり, $L=800, K=402$ で $E=3.00 \times 10^{-5} \operatorname{dot}$ となり 十分に小さい。FIHT3 の近似誤差は 0 である。以上は溸化 式に乗算を用いた場合の近似誤差である。

漸化式にシフト演算を用いた場合の計算誤差は(22)式よ り，理論誤差のない FIHT3 で $2^{-(p+2)} K$ である。 $[K]=402, p=22$ とすると， $E=2.40 \times 10^{-5} \mathrm{dot}$ となる。続いて Nakashima らの 手法における計算誤差について考察する。この手法では 1 点あたりの計算にシフト演算を 2 回必要とする。このため, 理論誤差 $E_{1}=\pi^{4} L /\left(40 K^{3}\right)$ とシフト演算 1 回による累積誤差 $E_{2}=2^{-(p+2)} K$ の 2 倍との総合誤差 $E$ を二乗和平方根から計算す ると,

$$
E \approx \sqrt{E_{1}^{2}+4 E_{2}^{2}}=\sqrt{\left(\pi^{4} L\right)^{2} /\left(40 K^{3}\right)^{2}+K^{2} 2^{-(2 p+2)}}
$$

となる。 $L=800,[K]=402$ とすると $E=5.66 \times 10^{-5} \operatorname{dot}$ である。 FIHT2 の場合は近似誤差が非常に大きいため, シフト演算 に伴う誤差の影響は受けず，乗算の場合の近似誤差と同じ である。

\section{4. 実 験}

本章では, FIHT2, Nakashima らの手法, 提案した FIHT3 の 3 手法で, Hough 曲線に対する偏差と計算速度を比較す る。改良 FIHT2 は, FIHT2 や Nakashima らの両手法と比べ て, Hough 曲線に対する近似誤差で劣るため除外した。計 算には, CPU に Pentium4-1.7GHz を搭載したパソコンを用い,

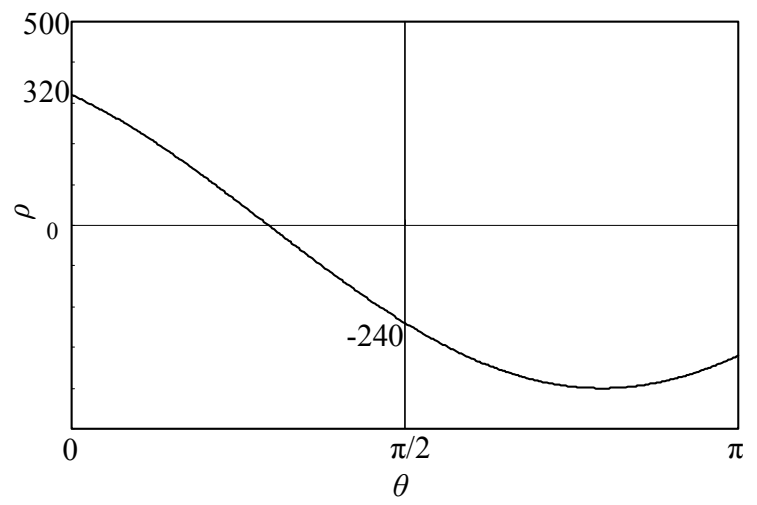

Fig. 4. Hough curve used in the experiment.

Table 4. Deviation to the Hough curve (multi).

\begin{tabular}{|c|c|c|c|}
\hline & FIHT2 & Nakashima & FIHT3 \\
\hline Theory & 1.25 & $3.00 \times 10^{-5}$ & 0 \\
\hline Experiment & 1.25 & $3.01 \times 10^{-5}$ & $2.84 \times 10^{-13}$ \\
\hline
\end{tabular}

Table 5. Deviation to the Hough curve (shift operation).

\begin{tabular}{|c|c|c|c|}
\hline & FIHT2 & Nakashima & FIHT3 \\
\hline Theory & 1.25 & $6.42 \times 10^{-5}$ & $2.40 \times 10^{-5}$ \\
\hline Experiment & 1.25 & $5.35 \times 10^{-5}$ & $1.60 \times 10^{-5}$ \\
\hline
\end{tabular}

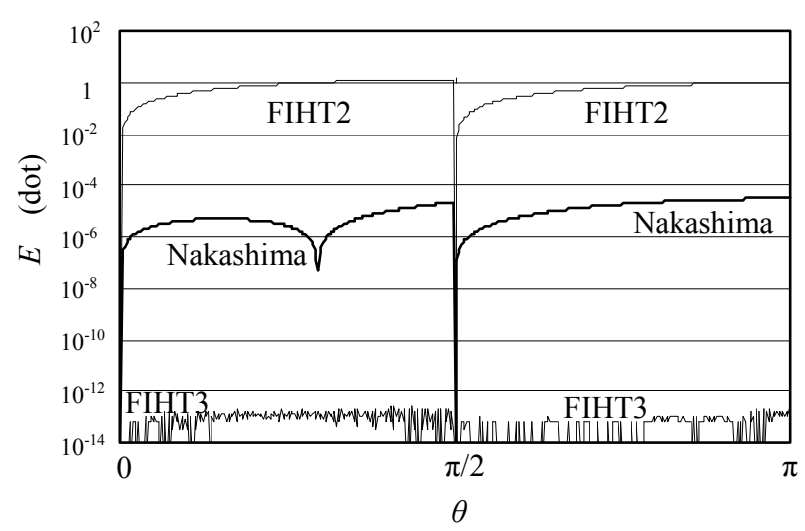

Fig. 5. Deviation $E$ to Hough curve (Multiplication).

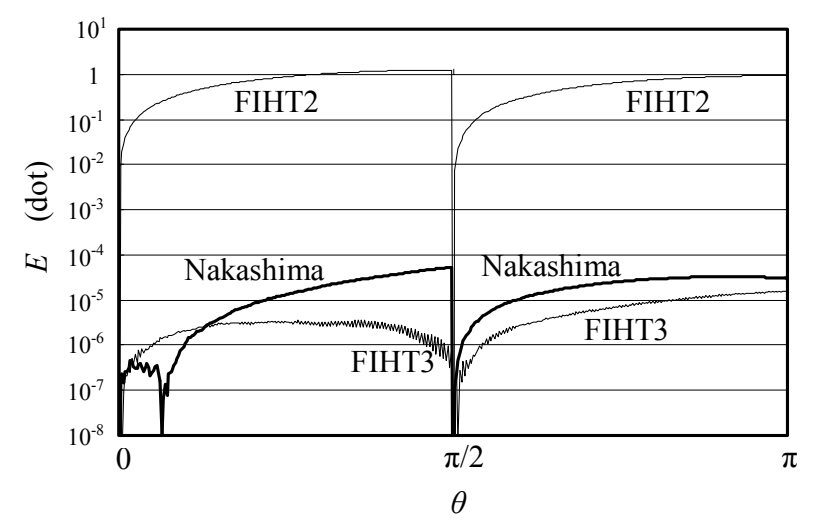

Fig. 6. Deviation $E$ to Hough curve (Shift operation). 


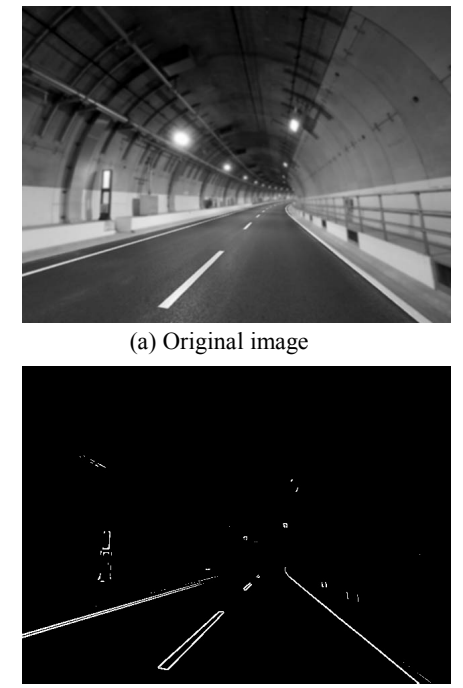

(b) Edge detected image

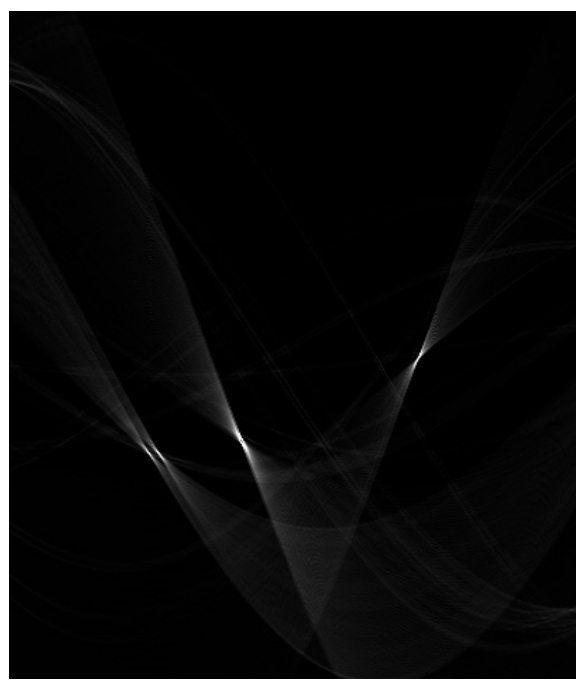

(e) Processed by FIHT2

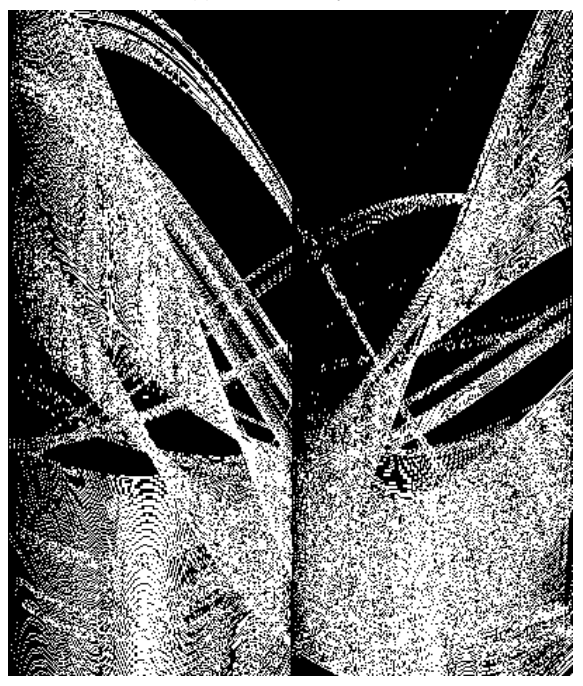

(h) Deviation (FIHT2)

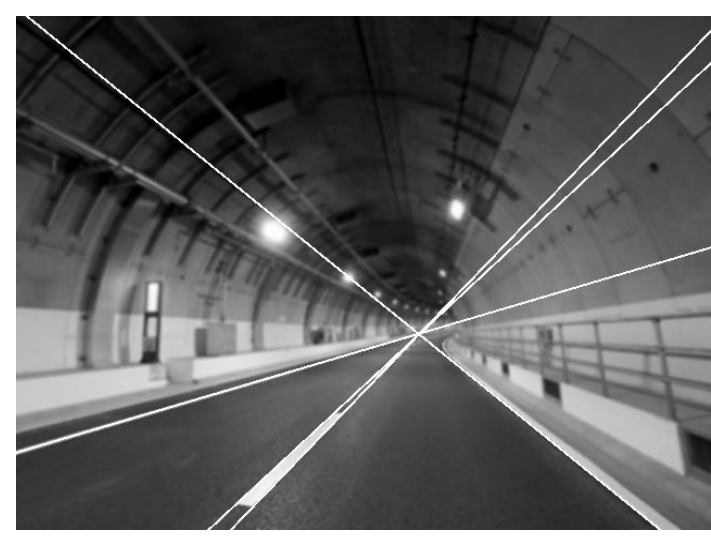

(c) Result of line detection by FIHT3

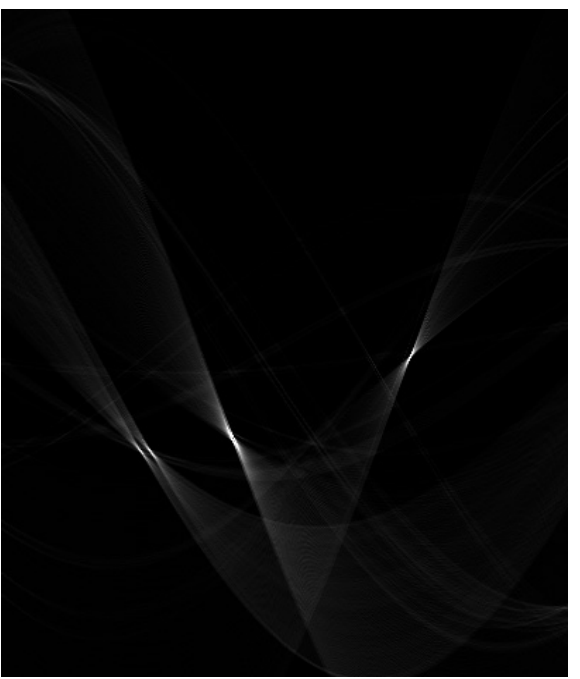

(f) Processed by Nakashima's method

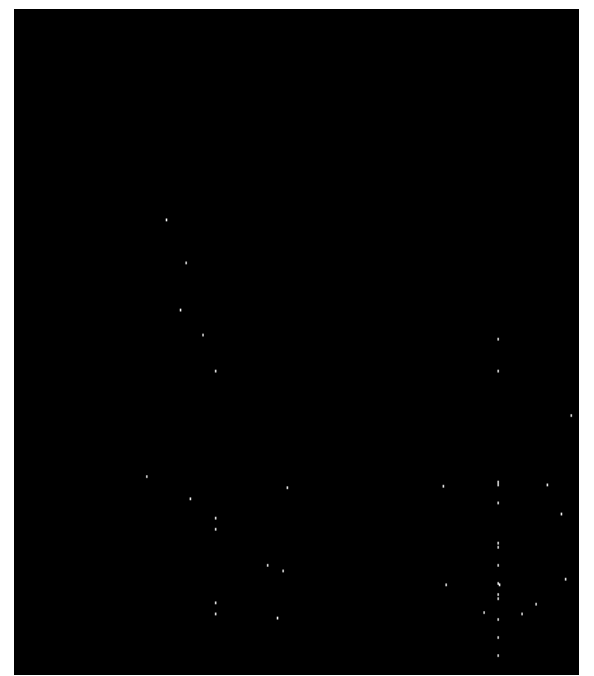

(i) Deviation (Nakashima's method)

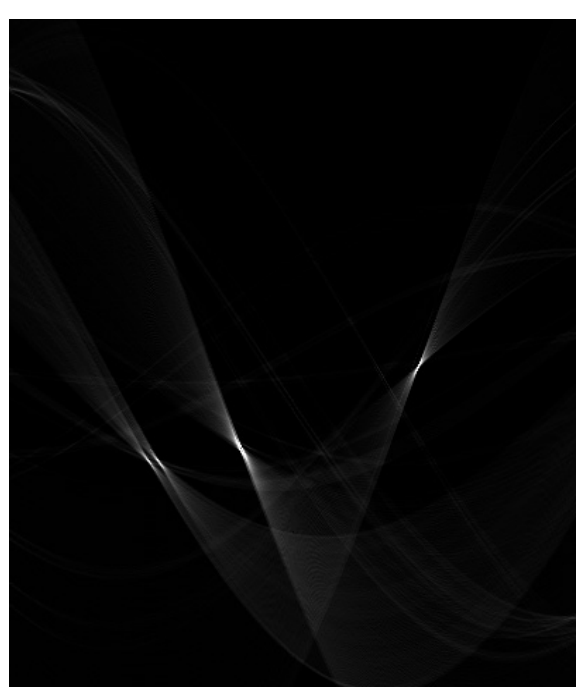

(d) Processed by Hough transform

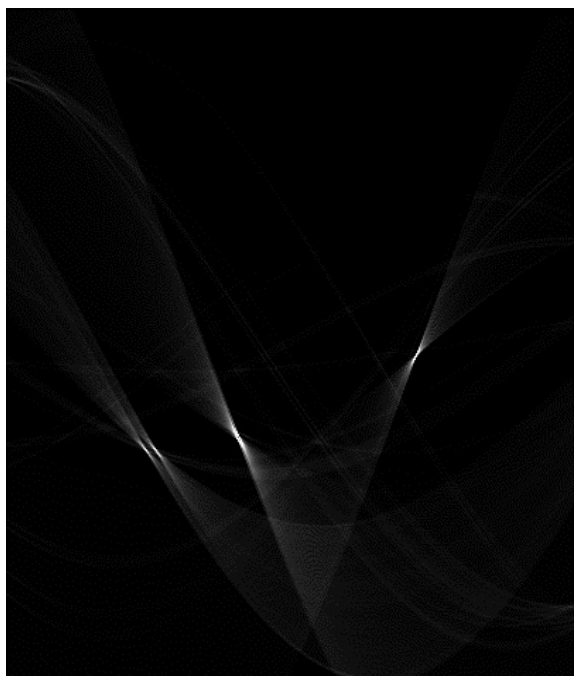

(g) Processed by FIHT3

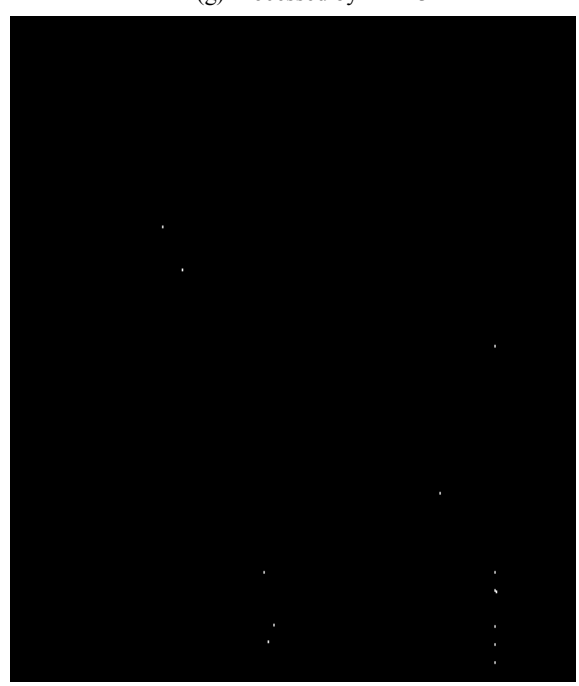

(j) Deviation (FIHT3)

Fig. 7. Deviation between Hough transform and other methods. 


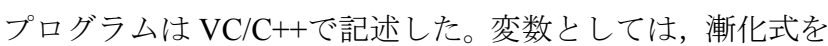
乗算で計算した場合で倍精度実数（64bit）, シフト演算を用 いて計算した場合で整数（32bit）を用いた。

〈4-1〉 Hough 曲線生成における偏差 画像中心に原 点をもつエッジ画像の大きさを H640 × V480 pixel, $\rho$ 方向分 割数を $L=800, \theta$ 方向分割数を $K=402$ とする。画像上のエッ ジ点の座標を $x=320, y=-240$ として, Hough 曲線または近似 Hough 曲線を発生させる。図 4 は( 1 )式で計算した, 実験で 用いる Hough 曲線である。これと， 3 手法で計算した曲線 との近似誤差を調べる。

表 4 に, 乗算を用いた場合の Hough 曲線と各手法との偏 差 $E$ を, 理論值と実測值とに分けて示す。理論值は表 3 よ り計算した。FIHT2の近似誤差は $\pi L / 5 K=1.25 \operatorname{dot}$ であったが,

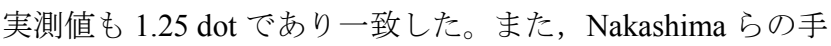
法の近似誤差は $\pi^{4} L /\left(40 K^{3}\right)=3.00 \times 10^{-5} \operatorname{dot}$ であったが, 実測值 も $3.01 \times 10^{-5}$ dot となりほぼ一致した。なお, FIHT3 の近似誤 差は 0 dot であるが，実測值は $2.84 \times 10^{-13}$ dot となった。こ れは倍精度計算における丸め誤差が，漸化式によって累積 されたものであり実用上は無視できる。FIHT3 の偏差は, 3 手法の中で最も偏差が小さかった。

シフト演算を用いた場合も同様にして計算し，表 5 に載 せた。各手法とも理論值と実験值は類似した值が得られた。 FIHT3 の偏差は 3 手法の中で最も偏差が小さく, 理論值・ 実験值ともに Nakashima らの手法の 1/2 から 1/3 以下であっ た。

図 5 は, Hough 曲線と 3 手法による計算值との偏差を, 漸化式を乗算で計算した場合で示したものである。 $\theta$ 範囲 を $0 \leq \theta<\pi$ とする。 $\theta=0, \pi / 2$ を除くすべての区間で FIHT3，

Nakashima らの手法, FIHT2 の順で偏差が小さくなった。 $\theta=0$, $\pi / 2$ で FIHT2 や Nakashima らの手法で FIHT3 よりも偏差が 小さくなるのは, ここが $\rho_{0}$ と $\rho_{0}^{\prime}$ との初期值として, Hough 曲線上の点が直接与えられるためにすぎない。

図 6 は, Hough 曲線と 3 手法による計算值との偏差を, 漸化式をシフト演算で計算した場合で示したものである。 $\theta$ の範囲を $0 \leq \theta<\pi$ とする。一部の区間で FIHT3 よりも Nakashima らの手法の偏差が小さい場合があるが，概ね， FIHT3, Nakashima らの手法, FIHT2 の順で偏差が小さくな った。

図 7 は Hough 変換と他の手法との変換画像における偏差 を, 実際の画像に適用して調べたものである。漸化式の計 算にはシフト演算を用いた。 $640 \times 480$ pixel の大きさを持つ 実際の画像(a)に, Sobel 法と 2 值化を適用してエッジ画像(b) を得た。(d),(e),(f),(g)がそれぞれ Hough 変換, FIHT2, Nakashima らの手法, FIHT3 による処理画像で, 横が $\theta$ 方向, 縦が $\rho$ 方向である。4つの画像はほぼ同じに見える。そこで 違いを明らかにするため, Hough 変換の処理画像(d)に対す る他の 3 手法の処理画像(e),(f),(g)のそれぞれの偏差の絶対 值をとり，1 以上のレベル差で白になるようにしたのが (h),(i),(j)である。FIHT2 ではレベル 1 以上の偏差を持つ画素 は 75589 点と $\rho-\theta$ パラメータ平面の $23.5 \%$ にも及んだ。こ
Table 6. Computational time (sec).

\begin{tabular}{|c|c|c|c|c|}
\hline & Hough & FIHT2 & Nakashima & FIHT3 \\
\hline Time & $1.34 \times 10^{-1}$ & $3.03 \times 10^{-2}$ & $2.84 \times 10^{-2}$ & $2.59 \times 10^{-2}$ \\
\hline Ratio & 5.17 & 1.17 & 1.10 & 1.00 \\
\hline
\end{tabular}

れに対し, Nakashima らの手法ではレベル 1 以上の偏差を持 つ画素は 78 点で $0.024 \%$, FIHT3 では 26 点で $0.008 \%$ に過ぎ ない。FIHT3 は FIHT2 に対してはもちろん, Nakashima の手 法に対しても精度的に優れていることがわかる。FIHT3に よる直線検出結果を図(c)に示す。

ところで，FIHT2 法による最大の偏差は投票值の極大点 近傍で発生しており，その值は 152 であった。Hough 変換 による直線検出は投票值の極大点の検出で行うため, この 近似誤差が直線検出に影響を与える可能性が大きい。これ に対し, Nakashima らの手法, FIHT3 では最大の偏差は 1 で しかなく，しかも投票值の極大点近傍では発生しなかった。 両手法とも極大点近傍で最大 1 の偏差が発生する確率は $0.01 \%$ のーダーと低い。このため，1dot 単位の整数值で極 大点の位置を検出する通常の Hough 変換では, 近傍データ の投票值がたとえ 1 増えてもそれが極大点の検出位置に及 ぼす影響は極めて小さいので，これら 2 手法の近似誤差が 直線検出に与える影響は 0 と考えてよい。しかし，近傍の 投票值にフィルタを適用し実数值で極大点の位置を検出す る高精度な Hough 変換では, 近傍データの投票值が 1 増え るだけでも極大点の検出位置に影響を及ぼす。この場合に は, Nakashima らの手法に比べて偏差の小さい FIHT3 の方 が直線検出に与える影響は小さい。なお, FIHT3 の処理画 像 $(\mathrm{g})$ の場合で漸化式の計算に乗算を用いると Hough 変換の 処理画像 $(\mathrm{d}) に$ 正確に一致する。このため, (j)の FIHT3 の偏 差画像の白画素数は 0 になる。

〈4·2〉 計算時間 Hough 変換に要する計算時間を測 定するため, 図 7 の(d),(e),(f),(g)の投票画像生成に必要な時 間を計測した。Hough 変換の計算には, 三角関数值テーブ ルを用いた高速手法を用いる。

表 6 に計算時間を示す。計算時間は FIHT3 が最も速く, 次いで Nakashima らの手法, そして FIHT2 の順であった。 FIHT3 に対する Nakashima らの手法の処理時間の比率は 1.10 倍とそれほど大差はない。これは, 投票画像生成にお いてメモリへの書き込み時間が大きなウェイトを占めるた め, もともと処理時間の小さな Shift 演算の回数が 2 倍違つ ても影響が現れにくいためと思われる。一方, FIHT3 に対 する FIHT2 の処理時間の比率は, シフト演算回数が同じで あるにも関わらず 1.17 倍であった。これは, 計算に用いた CPU が複数の命令を同時に実行できるスーパースケーラ技 法を用いているため, 並列演算方式の利点が出たものと思 われる。このため, 提案手法はハードウェア化に適した手 法であることが確かめられた。なお，三角関数テーブルを 用いず, (1)式をそのまま計算するオリジナルの Hough 変換 の計算時間は $5.23 \times 10^{-1} \mathrm{sec}$ であった。FIHT3 に対する処理 時間の比率は 20.2 におよぶ。 


\section{5. まとめ}

FIHT2 のように漸化式を用いたインクリメンタルな計算 法でありながら，近似ではなく㛜密に Hough 曲線を生成で きる手法 FIHT3 を提案した。この手法の基本演算部の乗算 回数はFIHT2 と同じく 1 回であり，ステップ数も FIHT2 と 同様 2 行と少ない。

Hough 曲線との偏差に関する実験では, FIHT3 は従来の 2 手法である FIHT2, Nakashima らの手法のいずれよりも偏差 が小さくかった。これは，漸化式の計算に乗算を用いた場 合でもシフト演算を用いた場合でも変わらない。さらに, エッジ画像から Hough 曲線による投票值画像を生成する実 験では，従来の 2 手法よりも高速であった。ただ，シフト 演算自体の計算コストが小さいため，投票值更新も含めた 計算時間では Nakashimaらの手法に対しては 1.1 倍しか速く なかったが，三角関数テーブルを用いる一般的な Hough 変 換と比べると 5.17 倍の高速化が可能であった。また， 1 点 あたりの乗算回数が直列演算方式の FIHT2 と同じであるに も関わらず，並列演算可能な CPU を用いると FIHT3 の方が 約 1.17 倍速くなったことから, ハードウェア化に適した演 算方式であることも確かめられた。

(平成 20 年 10 月 2 日受付, 平成 20 年 12 月 12 日再受付)

\section{文献}

(1) R. O. Duda and P. E. Hart : "Use of the Hough transform to detect lines and curves in pictures", Comm. ACM, Vol.15, No.1, pp.11-15 (1972)

(2) S. M. Karabernou, L. Kessala, and F. Terranti : "Real-time FPGA implementation of Hough Transform using gradient and CORDIC algorithm", Image and Vision Computing, Vol.23, pp.1009-1017 (2005)

( 3 ) D. Ben-Tzvi, A. A. Naqvi, and M. B. Sandler : "Synchronous multiprocessor implementation of the Hough transform, Computer Vision", Graphics and Image Processing, Vol.52, No.3, pp.437-446 (1990)

(4) J. E. Vuillemin : "Fast Linear Hough Transform, International Conference on Application Specific Array Processors", pp.1-9 (1994)

(5) G. Bongiovanni, C. Guerra, and S. Levialdi : "Computing the Hough transform on a pyramid architecture", Machine Vision and Applications, Vol.3, pp.117-123 (1990)

(6) R. Cucchiara and F. Filicori : "The vector-gradient Hough transform", IEEE Trans. Pattern. Anal. Machine Intell., Vol.20, No.7, pp.746-751 (1998)

( 7 ) F. O' Gorman and M. B. Clowes : "Finding picture edges through collinearity of feature points", IEEE Trans. Computers, Vol.25, No.4, pp.449-456 (1976)

（8）恩田邦夫・青木由直：「三角関数の周期性を利用した Hough 変換の 高速計算法」, 信学論, 70-D, 10, pp.2009-2011 (1987)

( 9 ) S. Tagzout, K. Achour, and O. Djekouse: "Hough transform algorithm for FPGA implementation, Signal Processing”, Vol.81, pp.1295-1301 (2001)

(10) H. Koshimizu and M. Numada : "FIHT2 algorithm, a fast incremental Hough transform”, IEICE Trans., Vol.E 74, No.10, pp.3389-3393 (1991)

(11) H. Koshimizu and M. Numada : "On a fast piece-wise linear Hough transform PLHT and its application", IAPR Workshop on CV-Special Hardware and Industrial Application, pp.335-339 (1988)

(12) K. Nakashima, H. Yakabe, Y. Obuchi, and K. Inoue : "High-speed, high-accuracy Hough transform using simultaneous recurrence formula", Systems and Computers in Japan, Vol.28, No.3, pp.24-33 (1997)

\section{付 録}

A.1 シフト演算を用いた FIHT3 プログラム

\#include $<$ math.h $>$

$\begin{array}{llll}\text { \#define } & \mathrm{L} & 800 & / / L \\ \text { \#define } & \mathrm{K} & 402 & / /[K] \\ \text { \#define } & \mathrm{Ds} & 0.007812579 & / / \Delta \theta\end{array}$

unsigned char* pointer1;

$/ /(\theta, \rho)$ pointer

pointer1=(unsigned char*)GlobalAlloc $(\mathrm{GPTR}, \mathrm{L} * \mathrm{~K})+\mathrm{L} / 2$;

int $\quad$ IR10, IR11, IR1; $\quad / / R_{0}, R_{1}, R_{2}$

int IR20, IR21, IR2; $\quad / / R_{0}^{\prime}, R_{1}^{\prime}, R_{2}^{\prime}$

double $\quad$ roh10, roh11, roh20, roh21; $\quad / / \rho_{0}, \rho_{1}, \rho_{0}^{\prime}, \rho^{\prime}{ }_{1}$ unsigned char* pointer $2=$ pointer $1+(\mathrm{K} / 2) * \mathrm{~L} ; \quad / /\left(\theta+\pi / 2, \rho^{\prime}\right)$ pointer ////////// FIHT3 ////////////////////////////////////////////////////////

void FIHT3(double $\mathrm{x}$, double y) $\quad$ //FIHT3 main loop

$$
\begin{array}{lc}
\operatorname{roh} 10=\mathrm{x} ; \operatorname{roh} 20=\mathrm{y} ; & / / \rho_{0}, \rho_{0}^{\prime} \\
\operatorname{roh} 11=\mathrm{x} * \cos (\mathrm{Ds})+\mathrm{y}^{*} \sin (\mathrm{Ds}) ; & / / \rho_{1} \\
\operatorname{roh} 21=-\mathrm{x}^{*} \sin (\mathrm{Ds})+\mathrm{y}^{*} \cos (\mathrm{Ds}) ; & / / \rho^{\prime}{ }_{1}
\end{array}
$$

$/ /\left(\theta_{0}, \rho_{0}\right),\left(\theta_{1}, \rho_{1}\right),\left(\theta_{0}^{\prime}+\pi / 2, \rho_{0}^{\prime}\right),\left(\theta_{1}^{\prime}+\pi / 2, \rho_{1}^{\prime}\right)$ countup

*(pointer1+(int)roh10) $+=1$; pointer $1+=\mathrm{L}$;

*(pointer1+(int)roh11) $+=1$; pointer $1+=\mathrm{L}$;

*(pointer2+(int)roh20) $+=1$; pointer $2+=\mathrm{L}$;

$*($ pointer $2+($ int $)$ roh 21$)+=1$; pointer $2+=\mathrm{L}$

$\operatorname{IR} 10=(\mathrm{int})(\operatorname{roh} 10 * 4194304.0) ; \quad / / R_{0}=\operatorname{int}\left(\rho_{0} \times 2^{22}\right)$

$\operatorname{IR} 11=($ int $)(\operatorname{roh} 11 * 4194304.0) ; \quad / / R_{1}=\operatorname{int}\left(\rho_{1} \times 2^{22}\right)$

$\operatorname{IR20}=(\mathrm{int})(\operatorname{roh} 20 * 4194304.0) ; \quad / / R_{0}^{\prime}=\operatorname{int}\left(\rho_{0}^{\prime} \times 2^{22}\right)$

$\operatorname{IR} 21=(\mathrm{int})(\operatorname{roh} 21 * 4194304.0) ; \quad / / R_{1}^{\prime}=\operatorname{int}\left(\rho_{1}^{\prime} \times 2^{22}\right)$

////////// FIHT3 main loop /////////////////////////////////////////

for(int $\mathrm{Ik}=0 ; \mathrm{Ik}<\mathrm{K} / 2-2 ; \mathrm{Ik}++)\{\quad / / k=0,1, \cdots,[K] / 2-3$

$\mathrm{IR} 1=\mathrm{IR} 10+(\operatorname{IR} 21>>6) ; \quad / / R_{k+2}$

$\mathrm{IR} 2=\mathrm{IR} 20-(\mathrm{IR} 11>>6) ; \quad / / R_{k+2}^{\prime}$

$\mathrm{IR} 10=\mathrm{IR} 11 ; \mathrm{IR} 20=\mathrm{IR} 21 ; \quad / / R_{k}, R_{k}^{\prime}$

$\mathrm{IR} 11=\mathrm{IR} 1 ; \quad \mathrm{IR} 21=\mathrm{IR} 2 ; \quad / / R_{k+1}, R_{k+1}^{\prime}$

if $(*($ pointer1+(IR1>>22) $)<255) / /$ over flow check

$*\left(\right.$ pointer $1+(\operatorname{IR} 1>>22)+=1 ; / /\left(\theta_{k+2}, \rho_{k+2}\right)$ count up

if $(*($ pointer2 $+(\operatorname{IR} 2>>22))<255) / /$ over flow check

$*\left(\right.$ pointer $2+(\operatorname{IR} 2>>22)+=1 ; / /\left(\theta_{k+2}+\pi / 2, \rho_{k+2}^{\prime}\right)$ count up

pointer $1+=\mathrm{L}$; pointer $2+=\mathrm{L}$; $\quad / /$ pointer count up

\}

\}

GlobalFree(pointer1); 


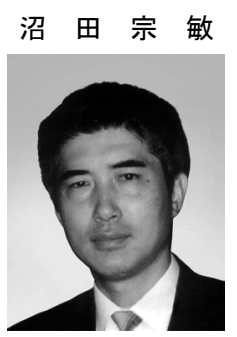

（非会員） 1984 年富山大学理学部物理学科卒 業。2006 年富山県立大学大学院工学研究科博士 後期課程修了。博士 (工学)。1984 年よりコマ ツ NTC グループ（株）ロゼフテクノロジー, コマツ NTC（株）等に勤務。2004 年より中京 大学人工知能高等研究所員兼任。2006 年より富 山県立大学工学部非常勤講師, 中京大学情報理 工学部非常勤講師などを歴任, 2009 年より中京 大学情報理工学部教授。主たる研究テーマは, 人工知能, 機械学習, 知能機械学, コンピュータグラフィックス, 画像処理。電子情報通 信学会, 情報処理学会, 精密工学会各会員。共著書に, 最新コンピ ユータグラフィックスがわかる（技術評論社）など。
舆 水 大 和 (上級会員) 1975 年名古屋大学大学院工学研究

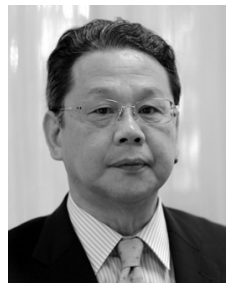
科博士課程修了。工学博士。名古屋大学助手, 名古屋市工研を経て, 現在中京大学情報理工学 部長。画像処理, マシンビジョン, パターン認 識, 顔研究, 画像デジタル化理論, Hough 変換 など画像処理基礎理論, およびそれらの産業応 用研究に従事。電子情報通信学会（教科書委 員), SICE (PM 部会顧問), JSPE (IAIP 副委員 長), 日本顔学会 (理事), 各種国内 - 国際学会 (SSII, ViEW, DIA/QCAV, FCV など) で活動中。共著書に, 画像処理基本技法（技 術評論社), コンピュータビジョン (近代科学社), 実践画像処理 (Springer-Verlag 東京), 信号処理（オーム社）など。ViEW2002 小 田原賞（IAIP，JSPE）など受賞。 